Journal of Agricultural Sciences
(Tarim Bilimieri Dergisi)

\title{
Identification of $S$-Allele Based Self-incompatibility of Turkish Pear Gene Resources
}

\author{
Merve Dilek KARATAŞ $S^{a} \mathbb{D}$, Nahid HAZRATI ${ }^{b} \mathbb{D}$, Ezgi OĞUZ $^{b} \mathbb{D}$, Canan YÜKSEL ÖZMEN ${ }^{b} \mathbb{D}$,

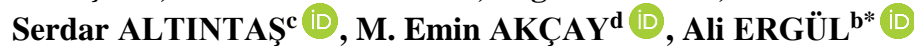

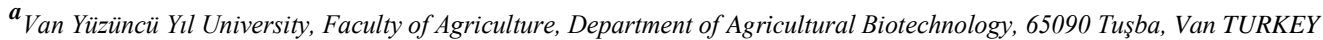

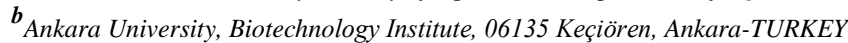

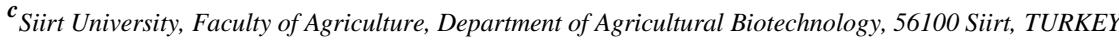

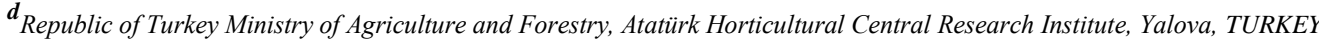

\section{ARTICLE INFO}

Research Article

Corresponding Author: Ali ERGÜL, E-mail: ergul@ankara.edu.tr

Received: 10 November 2020 / Revised: 09 April 2021 / Accepted: 11 April 2021 / Online: 25 March 2022

\section{ABSTRACT}

Self-incompatibility is considered to be a growth-limiting factor in fruit plants. In species with hermaphrodite flowers, $S$-locus ( $S$-allele) has been accepted to control self-incompatibility, and the genetic control of this locus is provided by multiple genes (alleles). Pear (Pyrus communis L.) belongs to the Pomoideae from the Rosaceae family and is found to have great genetic potential in terms of ecological features in Turkey. To protect these cultivation features, national garden collections have been established across the country and Atatürk Horticultural Central Research Institute-Yalova collection is considered as genes bank Identification of the different features of this collection (fruit quality, stress tolerance, self-incompatibility, grafting incompatibility, etc.) is of great importance for its utilization in pear breeding and cultivation. However, to our knowledge, this collection has not been characterized for self-incompatibility trait. In the current study, PCR (Polymerase Chain Reaction)-based amplification of the $S$-allele regions $\left(S_{1}, S_{6}, S_{7}\right.$, $S_{8}$ ) causing the self-incompatibility in 180 pear genotypes obtained from the national pear germplasm was investigated by molecular biological methods based on the comparison of amplified products. In 180 pear genotypes, the $S_{6}$ allele was the most prevalent one with $63 \%$ frequency, while the $S_{8}$ allele was the least common allele with a rate of $4 \%$. In allele combinations, the $S_{1-} S_{6}$ allele combination was the most common allele combination with a rate of $18 \%$, and trilateral allele combinations $\left(S_{1}-S_{6}-S_{7}\right.$ and $\left.S_{1}-S_{6}-S_{8}\right)$ were observed at a rate of $1 \%$. Findings of the current research will enable the classification of the materials and the analysed material is likely to be used in breeding studies as well as pear cultivation

Keywords: Pear genotypes, self -incompatibility, $S$-allel, PCR amplification

(C) Ankara University, Faculty of Agriculture

\section{Introduction}

Pear (Pyrus communis L.), is common fruit grown in almost all moderate climates especially in Europe and Asia. In Turkey, Anatolia area is considered as the homeland and/or diversity centre for many fruit trees. About 640 different pear genotypes have been found in the country. To protect these gene sources, local nominated genotypes in different eco-geographical regions have been collected and protected within this area (Akçay et al. 2014).

Self-incompatibility (SI) in flower-bearing plants is known as a failure in self-fertilization, which may be controlled genetically. Self-incompatibility is known as an unfavourable feature in successful fertilization and fruit set. This phenomenon has been found in more than 100 plant families and has been reported in nearly $40 \%$ of plant species (Igic et al. 2008) involving some major crop plants like pome, potato, canola, cocoa, olive, stone fruits, coffee, etc. and/or wild relatives of the mentioned crops. In the majority of plants, genetic control of self-incompatibility is done by a single multiallelic locus named $S$-locus however, control of the systems by two or more loci in some crops like grasses has also been identified (De Nettancourt 2001). Determinants of both female and male specificity which their products are expected to interact and operate the function of self or non-self-distinction are encoded by the $S$-locus (Iwano \& Takayama 2012; Muñoz-Sanz et al. 2020).

Depending on the function time of the gene in the stamen, most SI types can be categorized as gametophytic or sporophytic. In sporophytic self-incompatibility (SSI), determination of the SI phenotype is defined by the diploid genotype of parental or pollen-donor plant (sporophyte) and in gametophytic SI (GSI), the SI phenotype is determined by the pollen gametophytic haploid genotype (gametophyte) (Hiscock \& Tabah 2003). At the molecular level, three mechanisms of the SI have been identified. In Brassicaceae, sporophytic self-incompatibility (SSI) has been identified while two separate types of gametophytic self-incompatibility (GSI) including S-RNase-based SI widely elucidated in Solanaceae and Rosaceae, and the Papaver based system relating to the programmed cell death (PCD) (Muñoz-Sanz et al. 2020). 
In GSI which is considered to be the most prevalent type of SI, the cross becomes completely compatible when the male parent (haploid pollen genome) and female parent (diploid pistil genome) contain entirely disparate $S$-genotypes without any common $S$-allele (for instance $S_{1} S_{2}$ x $S_{3} S_{4}$ ). In case one $S$-allele is shared by the parents (for instance $S_{1} S_{2}$ x $S_{1} S_{3}$ ), proceeding of the pollen tube containing the similar allele is inhibited by pistil and consequently, the cross is considered to be semi-compatible. Accordingly, in case the same $S$-alleles are carried by the parents at the self-incompatibility locus (for instance $S_{1} S_{2} \times S_{I} S_{2}$ ), growth of the pollen cannot be happened on stigma. In other words, in case pistil-pollen couples do not include the same alleles, include at least one similar allele, or include several alleles, full compatibility, semi-compatibility or incompatibility is encountered, respectively. In crosses with the semi-compatible behaviour, half of the existing pollens are inhibited and could affect the yield and fruit set significantly, for example in Japanese plums, European pears and apple (Schneider et al. 2005; Zisovich et al. 2005; Goldway et al. 2008; Sapir et al. 2008). Results of the incompatibility are observed in minimum seed set and consequently, higher rates of small fruit formation, and yield loss.

Though GSI system applies similar genes in different taxa to specify the pollen rejection system, the mechanism elaboration differs significantly. Moreover, in all families, at least two linked genes or often more, are involved in $S$-locus consisting of a set of pollen-expressing SFBB genes (S-locus F-Box Brothers) and a pistil-expressed $S$-RNase gene. Pistil-expressed glycoproteins which show ribonuclease activity are encoded by $S$-RNase and they function as extremely selective cytotoxins which result in inhibition of pollens germination and growth when pollen single $S$-haplotype corresponds to one of the diploid pistil $S$-haplotypes (Sanzol \& Robbins 2008; Gao et al. 2015; Claessen et al. 2019; Muñoz-Sanz et al. 2020). Another is an F-box protein gene which is distinctly expressed in pollen, is named $S F B$ or $S L F$ according to the family (De Franceschi et al. 2012; Bagheri \& Ershadi 2019; Muñoz-Sanz et al. 2020).

Ability to predict the genomic structure of the pear $S$-locus has been performed using BAC cloning and sequencing in the Japanese pear (Pyrus pyrifolia) (Sassa et al. 2007). This was the first study to reveal the existence of several $S F B B$ genes surrounding the $S$-RNase. Comparing the genomic sequence surrounding the $S 2$ - and $S 4$-RNases, elucidated meaningful changes in the orientation and position of the $S F B B$ genes in pear $S$-haplotypes compared to the $S$-RNase gene (Okada et al. 2011; Claessen et al. 2019).

In Rosaceae and Solanaceae, $S$-haplotypes have 16 to $20 S L F$ gene sequences which collectively contribute to SI function of the pollen (Kubo et al. 2010; Kakui et al. 2011; Williams et al. 2014; Muñoz-Sanz et al. 2020). Sequence alignment of the $S$ RNase amino acid revealed five regions with the conserved characteristics (i.e. C1, C2, C3, C4, and C5) along with a highly variable region. In addition, a highly polymorphic intron located between the $\mathrm{C} 2$ and $\mathrm{C} 3$, is found in the hyper variable region (De Franceschi et al. 2012; Bagheri \& Ershadi 2019).

2D-PAGE (Two-dimensional Polyacrylamide Gel Electrophoresis) technique has been used to determine mentioned $S$ genotypes earlier. Despite being a fast technique, it is not preferred by plant breeders because it is not a reliable and easy method (Ishimizu et al. 1996). In the following years, PCR technique was applied to identify protected nucleotide sequences of $S$ - $R N a s e$. Zuccherelli et al. (2002) isolated $2 S$-allele DNA fragments in Japanese pear and proved that their sequences are similar to that of databank sequences. Among them, $6 S$-allele fragments $\left(S_{a}, S_{b}, S_{c}, S_{d}, S_{e}\right.$ and $\left.S_{h}\right)$ have been cloned and sequenced. Using these alleles, the $S$-allele genotyping was performed in 10 pear genotypes (Barlett, Cascade, Doyennedu Comice, Abbé Fétel, Beurré Hardy, Passe Crassane, Conference, Beurré Bosc, Max Red Bartlett, Eletta Morettini), and the molecular data obtained were confirmed by field crossing results. In the study, PCR based $S$-allele genotyping at molecular level has been shown to be more fast and valid method for European pears.

A similar result was reported by Sanzol \& Robbins (2008), that partially $S$-genotyped European pear cultivars and semi compatible test-crosses of these cultivars resulted in the identification of $14 S$-alleles $\left(S_{1}\right.$ to $\left.S_{14}\right)$ at the phenotypic level and allelespecific PCR led to the distinction across S-RNases that yielded amplification products with similar size using appropriate primers. The authors concluded that these two procedures presented a system for discrimination of all fourteen $S$-alleles in European pear at the molecular level.

Although self-pollination could have occurred in pear, the commercial-scale production depends on the existence of at least two simultaneously flowering compatible cultivars to enable appropriate and effective cross-fertilization so, exploiting of self and inter-compatible cultivars are important for economic fruit set (Zisovich et al. 2010; Goldway et al. 2012). In addition, in last decades, repeated use of scant numbers of cultivars in fruit breeding programs led to increase in cross-incompatibility property as well as a narrow genetic base in new pear varieties (Sanzol \& Herrero 2002; Bagheri \& Ershadi 2019). In this point of view, identification of the $S$-genotypes of the given species is important for revealing the species and inter-species fertilization biology to proper utilization in breeding programs (Quinet et al. 2014).

Although the incompatibility has been investigated in many pear germplasms, no findings relating to the selfcompatibility/incompatibility have been encountered in genotypes of Turkey. In this paper, we evaluated the $S$-allele profiles of the pear genotypes of Turkey national collection in terms of fertilization biology. 


\section{Material and Methods}

\subsection{Plant material}

180 pear (Pyrus communis L.) genotypes were obtained from the Atatürk Horticultural Central Research Institute, Yalova, Turkey, as plant material (Supplementary Table 1).

Table 1- Primer sequences for allele-specific PCR

\begin{tabular}{llll}
\hline Primer & Forward (5'-3') & Reverse (5'-3') & PCR product size \\
\hline Pyrus $_{1} * *$ & aatgtaagactacagccctg & tccaccagtggcctgtttg & $367 \mathrm{bp}$ \\
Pyrus $_{6} *$ & gtttgtggccttcaaacgacg & gtgatcctttaaaagaactgc & $347 \mathrm{bp}$ \\
Pyrus $_{7} * *$ & tcacccagaaaattgcactaatgc & ccagtggcctttgtattcccaa & $352 \mathrm{bp}$ \\
Pyrus $_{8} * *$ & gtcattgacggggttgaaccc & ccaactgggctttgagtgat & $218 \mathrm{bp}$ \\
\hline
\end{tabular}

*: Ishimizu et al. (1999); **: Nashima et al. (2015)

\subsection{Polymerase chain reactions $(P C R)$}

Genomic DNA was isolated from the pear leaves according to Lefort et al. (1998). Determination of the DNA quantity was performed using Nanodrop ND-100 spectrophotometer and extracted DNA was checked on 1\% agarose gel.

Allele-specific primers were applied for identifying the single alleles $\left(S_{1}, S_{6}, S_{7}, S_{8}\right)$. Nucleotide sequences of $P y r u s S_{1}$, Pyrus $S_{6}$, Pyrus $S_{7}$, and Pyrus $S_{8}$ primers were obtained according to Ishimizu et al. (1999) and Nashima et al. (2015), respectively (Table 1). Optimization of PCR (BioRad T100 $\left.{ }^{\mathrm{TM}}\right)$ was conducted for used primers as follows: $5 \mathrm{X}$ PCR reaction buffer, $25 \mathrm{mM} \mathrm{MgCl} 2,100 \mu \mathrm{M}$ dNTP, 5 pmol primer, 5U Taq polymerase and 50-250 ng of genomic DNA was performed at a total volume of $15 \mu \mathrm{L}$. Negative control was conducted for controlling each PCR contamination. PCR program was performed as follows; 3 minutes pre-denaturation at $94{ }^{\circ} \mathrm{C}, 10$ cycles $\left(94{ }^{\circ} \mathrm{C} 1 \mathrm{~min} ; 65^{\circ} \mathrm{C} 1 \mathrm{~min} 45 \mathrm{~s} ; 72{ }^{\circ} \mathrm{C} 2\right.$ min; reducing the annealing temperature by $1{ }^{\circ} \mathrm{C}$ each cycle), 20 cycles $\left(94{ }^{\circ} \mathrm{C} 1 \mathrm{~min} ; 50{ }^{\circ} \mathrm{C} 1 \mathrm{~min} 45 \mathrm{~s} ; 72{ }^{\circ} \mathrm{C} 2 \mathrm{~min}\right.$ ) and final extension was performed at $72{ }^{\circ} \mathrm{C}$ for 10 minutes.

\subsection{Evaluation of S-alleles according to band profiles}

Amplified PCR products were separated by $2 \%$ agarose gel electrophoresis along with DNA marker (Solis Byodyne) in $100 \mathrm{~V}$ for 1 hour and thereafter, DNA bands were visualized using a visualization system (Gene Genius Bio Imaging System) (Figure 1).
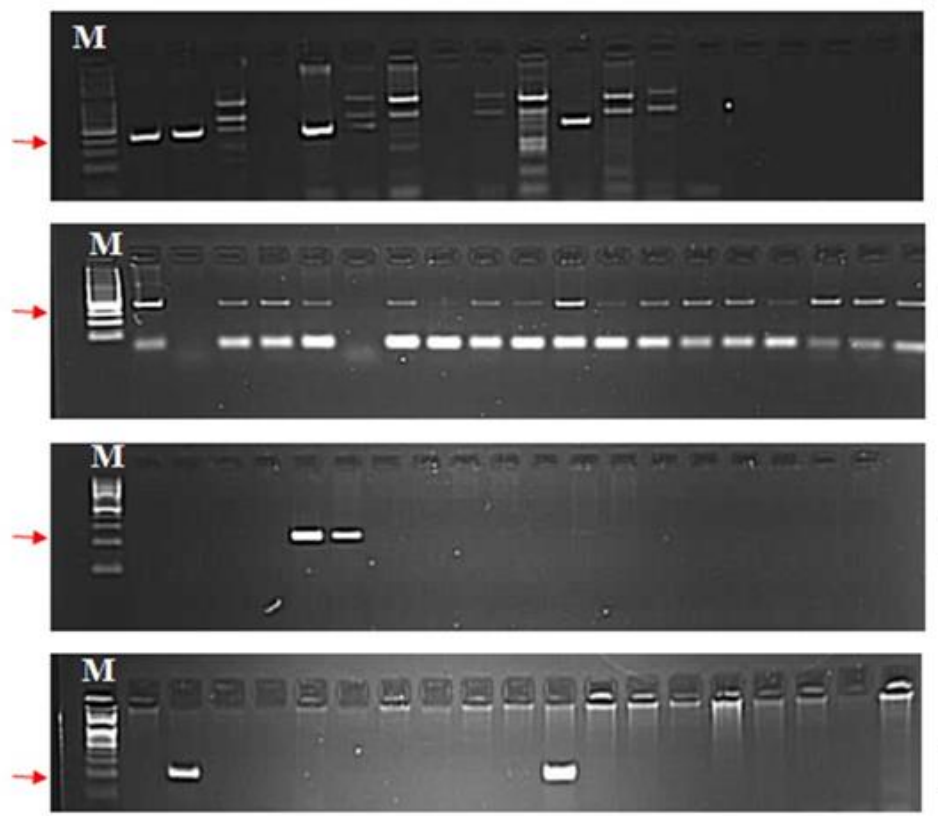

Figure 1- Examples of $S$-allele-specific PCR amplification images $\left(S_{1}, S_{6}, S_{7}\right.$ and $S_{8}$ respectively). M: 100bp DNA ladder 
After agarose gel visualization, genotypes with 367 bp (base pairs) in Pyrus $S_{1}$ primer, 347 bp in Pyrus $S_{6}$ primer, 352 bp in Pyrus $_{7}$ primer, and 218 bp in Pyrus $S_{8}$ primer were considered self-incompatible for the relevant $S$-allele. Allele distribution features determined by Broothaerts et al. (1996) and Ishimizu et al. (1999) have been considered in evaluation of the results.

Among four $S$-alleles, genotypes with at least one-two of which were accepted as semi-compatible, genotypes without amplified fragments were introduced as compatible, and the genotypes with three $S$-alleles are considered to be incompatible.

\section{Results and Discussion}

By identifying self-incompatibility in genotypes at molecular levels using $S$-alleles, findings of the pear gene resources have been revealed in Turkey (Supplementary Table 1).

\subsection{Relationship of compatibility and genetic similarity}

Two homonyms of Yalova pear genotypes named "Göksulu (Malatya)" and "Göksulu” (Akçay et al. 2014), showed to possess no similar $S$-alleles and were determined to be semi-compatible.

According to Akçay et al. (2014), “150 887 (1-5)" and "240 887 (3-3)" genotypes with a similarity rate of 91.7\% were observed to contain same $S$ allele $\left(S_{6}\right)$. Also, in "Bey Armudu" and "16" genotypes, with 91.7\% similarity, the first genotype contained $S_{6}$ allele while the other one was identified to be whole compatible (Supplementary Table 1).

\subsection{Relationship of compatibility and triploidy}

In a trial, genetic analyses using 18 SSR loci in 11 pear genotypes revealed presence of three alleles in 4-10 loci, and these genotypes have been identified as potential triploid genotypes (Akçay et al. 2014). In the current study, high variation of SSR alleles detected earlier, was not observed in incompatibility alleles and the $S_{6}$ allele was the most observed allele in these triploid incompatible genotypes and while there was no incompatibility allele observed in other 5 genotypes (A 2411, E. Buzbağ, A 2407, 265 GFAE, 140887 (2-2)) the rest showed at least one incompatible allele (Table 2).

Table 2- Self-incompatibility states of triploid genotypes in SSR analyses

\begin{tabular}{lll}
\hline $\begin{array}{l}\text { Triploids pear genotypes in SSR } \\
\text { analysis }\end{array}$ & Incompatibility allele & PCR based- Incompatibility status \\
\hline $190887(3-7)$ & $S_{6} S_{6}$ & Semi-compatible \\
$140887(2-1)$ & $S_{6} S_{6}$ & Semi-compatible \\
A 2412 & $S_{1} S_{6}$ & Semi-compatible \\
A 2404 & $S_{6} S_{6}$ & Semi-compatible \\
A 2401 & $S_{6} S_{7}$ & Semi-compatible \\
A 2411 & - & Compatible \\
E. Buzbağ & - & Compatible \\
A 2407 & - & Compatible \\
265 GFAE & - & Compatible \\
$140887(2-2)$ & - & Compatible \\
\end{tabular}

Table 3- $S$-Alleles, self-incompatibility cases and numbers

\begin{tabular}{llc}
\hline S allele & Number of genotypes & PCR based-Incompatibility status \\
\hline$S_{6} S_{6}$ & 69 & Semi-compatible \\
$S_{6} S_{7}$ & 4 & Semi-compatible \\
$S_{6} S_{8}$ & 2 & Semi-compatible \\
$S_{7} S_{7}$ & 5 & Semi-compatible \\
$S_{8} S_{8}$ & 3 & Semi-compatible \\
$S_{1} S_{1}$ & 14 & Semi-compatible \\
$S_{1} S_{6}$ & 33 & Semi-compatible \\
- & 46 & Compatible \\
$S_{1} S_{6} S_{8}$ & 2 & Incompatible \\
$S_{1} S_{6} S_{7}$ & 2 & Incompatible \\
\hline
\end{tabular}




\subsection{Identification of alleles and compatibility}

To improve the knowledge of self-incompatibility and its relations to many new pear genotypes, we elucidated $S$-genotype of 180 pear genotypes and arranged them based on their $S$-RNase alleles in 10 incompatibility groups (Table 3). Our results revealed incompatibility relations among a great number of pear genotypes in Turkey with unknown previous pollination requirements. These findings of given genotypes will be beneficial for indicating the potential of fertilization and fruit set, establishing the isolated gardens, and selecting as pollinizer.

In this research, four different $S$-alleles $\left(S_{1}, S_{6}, S_{7}, S_{8}\right)$ whose primers have been identified in similar work (Kim et al. 2002; Nashima et al. 2015) were optimized and band size of 180 pear genotypes was determined. 130 out of 180 genotypes which contained at least one $S$-allele were identified as semi-compatible. From the rest, 4 of which containing three $S$-allele were determined as incompatible. In 46 genotypes, it was not observed any $S$-allele and being different from the others, they were identified as compatible genotypes (Table 3 ).

$S_{6}$ allele was observed with $63 \%$ rate followed by $S_{1}$ with $28 \%$ rate. $S_{8}$ was the less observed $S$-allele with $4 \%$ rate. The highest bilateral $S$-allele combination was observed in $S_{1}-S_{6}(18 \%)$, and the highest trilateral combinations were $S_{1}-S_{6}-S_{7}$ and $S_{1}-S_{6}-S_{8}(1 \%)$. Quadripartite combination was not observed in any genotype.

In terms of $S_{1}, S_{6}, S_{7}$, and $S_{8}$ alleles, 46 genotypes (25\%) contained none of them, 91 genotypes (50\%) contained one of them, 39 genotypes (21\%) contained two of them, and 4 genotypes (2\%) contained three of them. No genotype containing all of the mentioned alleles was observed (Table 3).

Similar to our work, 14 Japanese pear genotypes were investigated using $11 S$-alleles including $S_{1}, S_{6}, S_{7}$, and $S_{9}$ alleles, and these alleles are applicable effectively for rapid identification of $S$-genotypes in similar pear breeding studies, and markerassisted selection (MAS) performing (Nashima et al. 2015). Low sequence similarity of allele introns (average 43\%) and high polymorphism in exon regions have been shown as the causes of high performance features of these $S$-alleles (Nashima et al. 2015). Nashima et al. (2015) identified existence of peculiar amplification (especially between $55-61{ }^{\circ} \mathrm{C}$ ) through various PCR optimization trials of the $S_{1}, S_{6}, S_{7}$, and $S_{9}$ primers, and observed undesirable fragments on agarose gel in all primer pairs under $100 \mathrm{bp}$. In our research, these primers were similarly optimized using Touch Down PCR ( $\mathrm{Tm}$ between 55-65 ${ }^{\circ} \mathrm{C}$ ) program and some non-specific band was observed among PCR products.

Nowadays, $S$-allele genotyping trials at molecular level have been accelerated. Up until now, $S$-allele cloning and sequencing has been performed in about 26 European pear genotypes. In addition, genotyping of S-RNase genes in more than 150 pear genotypes has been carried out (Sanzol \& Herrero 2002; Zuccherelli et al. 2002; Zisovich et al. 2004; Sanzol et al. 2006; Takasaki et al. 2006; Sanzol \& Robbins 2008; Goldway et al. 2009; Sanzol 2009 a, b; Nashima et al. 2015).

In our study, since the high numbers of genotypes possess $S_{6}$ allele, so this allele was chosen as the prevalent one. The high ratio of genotypes bearing the $S_{6}$ allele (112 out of 180 genotypes) in comparison to genotypes bearing $S_{l}$ and other two alleles, could be explained by a plausible hypothesis that the $S_{6}$-locus is linked to another gene or genes encoding an important trait for pear cultivation or quality so, it could be mentioned that the $S_{6}$ allele involved a selective preference during breeding. A previous study on European pears revealed that certain $S$-alleles have considerably more frequency, and selection for commercial traits was proposed to describe this result. In this regard, Sanzol \& Robbins (2008) noted that the majority of selected offspring of "Williams Bon Chrétien" cultivar with PcS101 and PcS102 S-alleles comprised the PcS101 allele rather than the PcS102 allele. The authors suggested that the PCS101 allele is of interest throughout selection. In addition, genetic analyses of species belonging to distant taxa are quite consistent with this feasibility (Burke et al. 2002; Gandhi et al. 2005). Nevertheless, it could be mentioned that the high use of certain genotypes as parent in breeding programs could also be one of the reasons for the abundance of certain alleles.

In our study, Williams cultivar was employed as a reference genotype and displayed an incompatible feature similar to previous studies (Sanzol \& Herrero 2002). $S$-allele-specific PCR analysis $\left(S_{1}, S_{6}, S_{7}\right.$ and $S_{8}$, respectively) are given in Figure 1 and the Williams cultivar representing reference genotype with known $S$-RNases $\left(S_{I} S_{6}\right)$, gave the expected PCR products corresponding to each allele and after electrophoresis, the higher frequency of $S_{6}$ allele was sensibly distinct among studied genotypes (Figure 1). Orcheski \& Brown (2012) noted that, since specific reference cultivars are often used as parent in breeding programs of new cultivars so, their related $S$-alleles are found frequently in new developed commercial cultivars.

In the current study, three alleles were found in the four genotypes, namely 'E2480 Kizll B1ldırcin' and 'E 2481 Kaymak' from Central Anatolian region and '21' and ' 52 ' from Marmara regions using these primers (Supplementary Table 1). According to 46 self-compatible genotypes, considering the proportion of regional samples, the highest proportion (40\%) with 13 out of 32 genotypes was assigned to the Marmara region and the lowest percentage with 3 out of 24 genotypes (12\% of the region samples) allocated to the Central Anatolian region so, more attention should be paid to contrivance, regarding the commercial production and orchard design in this region. The results confirmed that the self-incompatibility feature tends to 
increase in species, which is contrary to the former reports indicating that most cultivars were compatible (Mehlenbacher et al. 1991; Herrera et al. 2018).

Although much progress has been gained in understanding how the SI system works, many points of ambiguity remain still unclear. It has been recently illustrated that the Pyrus SI response begins with the uptake of the $S$-RNase protein from the style transmitter tissue by the pollen tube in a non-allelic specific manner. The entry of both non-self and self $S$ - $R N a s e s$ into the pollen tube, support that the process of self-recognition takes place inside the pollen tube and subsequently results in inhibition of the non-self $S$-RNases activity (Goldraij et al. 2006; De Franceschi et al. 2012; Meng et al. 2014a; Meng et al. 2014b, Williams et al. 2015). In Malus and Pyrus species, the simultaneous attendance of multiple SFBB genes on the $S$-locus as the pollen $S$-detectors (Sassa et al. 2007) indicates that each of the SFBB proteins may detect one or more non-self $S$-RNases, targeting them for proteasome degradation (De Franceschi et al. 2012).

The recognition system has been proposed to occur via two models for GSI in Pyrus species. In the first model, the SFBB protein which identifies specifically the self $S$-RNase, relinquishing the self $S$-RNase intact to reject extension of the incompatible (self) pollen tube while mark all non-self $S$-RNases (Williams et al. 2015). In the second model which functions in the non-self-recognition way, the multiplex $S F B B$ s that each distinguish and target a subset or unique non-self $S$-RNases, resulted in $S$-RNase decomposition so, the self $S$-RNases which are not prohibited led to the inhibition of self-incompatible pollen growth (Kubo et al. 2010).

It should be noted that in nature, true rejection of pollen is not only controlled genetically but also is affected by various external agents, like the environmental factors and pollination grade resulting in selfed seeds in self-incompatible varieties (Visser \& Marcucci 1984). Interestingly, in cases where pollination occurs by non-self pollen, the evolvement possibility of ovule or fruit is higher than in case of self-pollination, which indicates the attendance of additional post-zygotic inhibitors that inhibit the selfed seed formation (Martin \& Lee 1993). It is concluded that this abortion could be caused by recessive homozygous alleles combination or accumulation of low alleles that occur as a result of self-fertilization (Pannell \& Labouche 2013) or due to the lower intake strength of plant sap for energy attainment.

Similarly, crosses between two semi-compatible lines could also lead to adversities. In semi-compatible crosses, half of the pollens bearing certain $S$-genotype are inhibited, resulting in a limited number of possible $S$-genotype compositions in the progeny. This "artificial selection" significantly affects the diversity of $S$-alleles, leading to a reduction in biological and genetic diversity as well as the loss of interesting traits in pear cultivars (Claessen et al. 2019).

According to the contents, examination of the pear SI mechanism reveals that in most commercial cultivars, the fruit set is highly depend on cross-pollination and successful fertilization. For these reasons, incompatibility is a system that nature has developed to prevent the accumulation of adverse homozygous allele damages and to provide a way to create varieties with diverse characteristics while maintaining viability over the years.

\section{Conclusions}

$S$-genotyping has made it possible to classify cultivars in relevant incompatibility groups considering their compatibility relations. Self-incompatibility is displayed when the pollen genotype corresponds to one of the pistil $S$-alleles. Therefore, selfincompatible lines bearing the similar $S$-alleles by classification in the identic incompatibility category, are considered to be inter-incompatible, while lines from other categories containing at least one different $S$-allele are accepted to be intercompatible (Muñoz-Sanz et al. 2017).

It should be noted that standardization of the $S$-alleles identification criteria is essential in various laboratories, including the full sequencing of $S$ alleles and utilization of the identic primer pairs. This will lead to easy $S$-allele identification without confusion and will provide valuable information for pear breeders (Herrera et al. 2018). Obtained results in this study make it possible to organize the incompatibility relationships between pear genotypes with former unknown pollination knowledge and provide the possibility to select suitable parents in designing new crosses in pear production and breeding programs. Besides, this work could be helpful for other Rosaceae fruit products with the same challenges encountered by pear.

\section{References}

Akçay M E, Burak M, Kazan K, Yüksel Özmen C, Mutaf F, Bakir M, Ayanoğlu H \& Ergül A (2014). Genetic analysis of Anatolian pear germplasm by simple sequence repeats. Annals of Applied Biology 164: 441-452. https://doi.org/10.1111/aab.12113

Bagheri M \& Ershadi A (2019). Self-incompatibility alleles in Iranian pear cultivars. Biocatalysis and Agricultural Biotechnology 27:101672. https://doi.org/10.1016/j.bcab.2020.101672

Broothaerts W, Verdoodt L, Keulemans J, Janssens GA \& Broekaert WF (1996). The self-incompatibility gene in apple and determination of the $S$-genotype of apple cultivars by PCR. Acta Horticulturae 423: 103-109. https://doi.org/10.17660/ActaHortic.1996.423.13

Burke J M, Tang S, Knapp S \& Rieseberg L H (2002). Genetic analysis of sunflower domestication. Genetics 162: 1257-1267 
Claessen H, Keulemans W, Van de Poel B \& De Storme N (2019). Finding a Compatible Partner: Self-Incompatibility in European Pear (Pyrus communis); Molecular Control, Genetic Determination, and Impact on Fertilization and Fruit Set. Frontiers in Plant Science 10: 407. https://doi.org/10.3389/fpls.2019.00407

De Nettancourt D (2001). Incompatibility and incongruity in wild and cultivated plants (Berlin Heidelberg: Springer-Verlag).

De Franceschi P, Dondini L \& Sanzol J (2012). Molecular bases and evolutionary dynamics of self-incompatibility in the Pyrinae (Rosaceae). Journal of Experimental Botany 63: 4015-4032. https://doi.org/10.1093/jxb/ers108

Gandhi S D, Heesacker A F, Freeman C A, Argyris J, Bradford K \& Knapp S J (2005). The self-incompatibility locus (S) and quantitative trait loci for self-pollination and seed dormancy in sunflower. Theoretical and Applied Genetics 111: 619-629. https://doi.org/10.1007/s00122-005-1934-7

Gao C, Yuan D Y, Yang Y, Wang B F, Liu D M \& Zou F (2015). Pollen tube growth and double fertilization in Camellia oleifera. Journal of the American Society for Horticultural Science 1401218. https://doi.org/10.21273/JASHS.140.1.12

Goldraij A, Kondo K, Lee C B, Hancock C N, Sivaguru M, VazquezSantana S, Kim S, Philips T E, Cruz-Garcia F \& McClure B (2006). Compartmentalization of S-RNase and HT-B degradation in self-incompatible Nicotiana. Nature 439: 805-810 https://doi.org/10.1038/nature04491

Goldway M, Stern R, Zisovich A, Raz A, Sapir G, Schnieder \& Nyska R (2012). The self-incompatibility system in Rosaceae: agricultural and genetic aspects. Acta Horticulturae 967: 77-82. https://doi.org 10.17660/ActaHortic.2012.967.7

Goldway M, Takasaki T, Sanzol J, Mota M, Zisovich A H, Stern R A \& Sansavini S (2009). Renumbering the S-RNase alleles of European pears (Pyrus communis L.) and cloning the S109 RNase allele. Scientia Horticulturae 119: 417-422. https://doi.org/10.1016/j.scienta.2008.08.027

Goldway M, Zisovich A, Raz A \& Stern R A (2008). Understanding the gametophytic self-incompatibility system and its impact on European pear (Pyrus communis L.) cultivation. Acta Horticulturae 800: 109-118. https://doi.org/10.17660/ActaHortic.2008.800.9

Herrera S, Rodrigo J, Hormaza J I \& Lora J (2018). Identification of self-incompatibility alleles by specific PCR analysis and S-RNase sequencing in apricot. International Journal of Molecular Sciences 19. https://doi.org/10.3390/ijms19113612

Hiscock S J \& Tabah D A (2003). The different mechanisms of sporophytic self incompatibility. Philosophical Transactions of the Royal Society of London. Series B: Biological Sciences 358: 1037-1045. https://doi.org/10.1098/rstb.2003.1297

Igic B, Lande R \& Kohn J R (2008). Loss of self-incompatibility and its evolutionary consequences. International Journal of Plant Sciences 169: 93-104. https://doi.org/10.1086/523362

Ishimizu T, Inoue K, Shimonaka M, Saito T, Terai O \& Norioka S (1999). PCR-based method for identifying the S-genotypes of Japanese pear cultivars. Theoretical and Applied Genetics 98(6): 961-967. https://doi.org/10.1007/s001220051156

Ishimizu T, Sato Y, Saito T, Yoshimura Y, Norioka S, Nakanshi T \& Sakiyama F (1996). Identification and partial aminoacid sequences of seven S-RNases associated with self-incompatibility of the Japanese pear, Pyrus pyriforia Nakai. Journal of Biochemistry 120: 326-334. https://doi.org/10.1093/oxfordjournals.jbchem.a021417

Iwano M \& Takayama S (2012). Self/non-self discrimination in angiosperm selfincompatibility. Current Opinion in Plant Biology 15: 7883. https://doi.org/10.1016/j.pbi.2011.09.003

Kakui H, Kato M, Ushijima K, Kitaguchi M, Kato S \& Sassa H (2011). Sequence divergence and loss-of-function phenotypes of $S$ locus $F$ box brothers genes are consistent with non-self recognition by multiple pollen determinants in self-incompatibility of Japanese pear (Pyrus pyrifolia). The Plant Journal 68: 1028-1038. https://doi.org/10.1111/j.1365-313X.2011.04752.x

Kim H T, Hirata Y \& Nou I S (2002). Identification of self incompatibility alleles by S-RNases sequencing and PCR-RFLP analysis in Korean-bred pear (Pyrus pyrifolia) strains. Acta Horticulturae 587:467-476. https://doi.org/10.10.17660/ActaHortic.2002.587.61

Kubo K, Entani T, Tanaka A, Wang N, Fields A M, Hua Z, Toyada M, Kawashima S, Ando T, Isogai A, Kao T \& Takaya S (2010). Collaborative non-self recognition system in S-RNase-based self incompatibility. Science 330: 796-799. https://doi.org/10.1126/science.1195243

Lefort F, Lally M, Thompson D \& Douglas G C (1998). Morphological traits microsatellite fingerprinting and genetic relatedness of a stand of elite oaks (Q. RoburL.) at Tuallynally, Ireland. Silvae Genetica 47: 5-6

Martin M E \& Lee T D (1993). Self pollination and resource availability affect ovule abortion in Cassia fasciculata (Caesalpiniaceae). Oecologia 94: 503-509. https://doi.org/10.1007/BF00566965

Mehlenbacher S A, Cociu V \& Hough F L (1991). Apricots (Prunus). Acta Horticulturae 290; 65-110 https://doi.org/10.17660/ActaHortic.1991.290.3

Meng D, Gu Z, Li W, Wang A, Yuan H, Yang Q \& Li T (2014a). Apple MdABCF assists in the transportation of S-RNase into pollen tubes. Plant Jornal 78: 990-1002. https://doi.org/10.1111/tpj.12524

Meng D, Gu Z, Yuan H, Wang A, Li W, Yang Q, Zhu Y, Li T (2014b). The microtubule cytoskeleton and pollen tube golgi vesicle system are required for in vitro S-RNase internalization and gametic self-incompatibility in apple. Plant \& Cell Physiology 55: 977989.https://doi.org/10.1093/pcp/pcu031

Muñoz-Sanz J V, Zuriaga E, Cruz-García F, McClure B \& Romero C (2020) Self-(In)compatibility Systems: Target Traits for CropProduction, Plant Breeding, and Biotechnology. Frontiers Plant Science 11: 195. https://doi.org/10.3389/fpls.2020.00195

Muñoz-Sanz J V, Zuriaga E, López I, Badenes M L \& Romero C (2017). Self-(in)compatibility in apricot germplasm is controlled by two major loci, S and M. BMC Plant Biology 17: 82. https://doi.org/10.1186/s12870-017-1027-1

Nashima K, Terakami S, Nishio S, Kunihisa M, Nishitani C, Saito T \& Yamamoto T (2015). S-genotype identification based on allelespecific PCR in Japanese pear. Breeding science 65(3): 208-215. https://doi.org/10.1270/jsbbs.65.208

Okada K, Tonaka N, Taguchi T, Ichikawa T, Sawamura Y, Nakanishi T \& Takeshi T Y (2011). Related polymorphic F-box protein genes between haplotypes clustering in the BAC contig sequences around the S-RNase of Japanese pear. Journal of Experimental Botany 62: 1887-1902. https://doi.org/10.1093/jxb/erq381

Orcheski B \& Brown S (2012). A grower's guide to self and cross incompatibility in apple. New York Fruit Quarterly 20: 25-28.

Pannell J R \& Labouche A M (2013). The incidence and selection of multiple mating in plants. Philosophical Transactions of the Royal Society of London. Series B: Biological Sciences 368: 20120051. https://doi.org/10.1098/rstb.2012.0051

Quinet M, Kelecom S, Raspe O \& Jacquemart A L (2014). S-genotype characterization of 13 North Western European pear (Pyrus communis L.) cultivars. Scientia Horticulturae 165: 1-4. https://doi.org/10.1016/j.scienta.2013.10.023

Sanzol J (2009a). Pistil-function break down in a new S-allele of European pear, S21, confers self-compatibility. Plant Cell Reports 28: 457467. https://doi.org/10.1007/s00299-008-0645-3

Sanzol J (2009b). Genomic characterization of self-incompatibility ribonucleases in European pear cultivars and development of PCR detection for 20 alleles. Tree Genetics Genomes 5: 393-405. https://doi.org/10.1007/s11295-008-0194-5 
Sanzol J \& Herrero M (2002). Identification of self-incompatibility alleles in pear cultivars (Pyrus communis L.). Euphytica 128:325-331. https://doi.org/10.1023/A:1021213905461

Sanzol J \& Robbins T P (2008). Combined analysis of $S$ alleles in European pear by pollinations and PCR based $S$-genotyping: correlation between S phenotypes and S-RNase genotype. Journal of the American Society for Horticultural Science 133: 213-224. https://doi.org/10.21273/JASHS.133.2.213

Sanzol J, Sutherland B G \& Robbins T P (2006). Identification and characterization of genomic DNA sequences of the S-ribonuclease gene associated with self-incompatibility alleles $S-1$ to $S-5$ in European pear. Plant Breeding 125: 513-518. https://doi.org/10.1111/j.14390523.2006.01269.x

Sapir G, Stern R A, Shafir S \& Goldway M (2008). S-RNase based Sgenotyping of Japanese plum (Prunus salicina Lindl.) and its implication on the assortment of cultivar couples in the orchard. Scientia Horticulturae 118: 8-13 https://doi.org/10.1016/j.scienta.2008.05.004

Sassa H, Kakui H, Miyamoto M, Suzuki Y, Hanada T, Ushijima K, Kusaba M, Hirano H \& Koba T (2007). S locus F-box brothers: multiple and pollen-specific $F$-box genes with $S$ haplotype-specific polymorphisms in apple and Japanese pear. Genetics 175: 1869-1881. https://doi.org/10.1534/genetics.106.068858

Schneider D, Stern R A \& Goldway M (2005). A comparison between semi and fully compatible apple pollinators grown under suboptimal conditions. HortScience 40: 1280-1282. https://doi.org/10.21273/HORTSCI.40.5.1280

Takasaki T, Moriya Y, Okada K, Yamamoto K, Iwanami H, Bessho H \& Nakanishi T (2006). cDNA cloning of nine $S$ alleles and establishment of a PCR-RFLP system for genotyping European pear cultivars. Theoretical and Applied Genetics 112: $1543-1552$. https://doi.org/10.1007/s00122-006-0257-7

Visser T \& Marcucci M C (1984). The interaction between compatible and self-incompatible pollen of apple and pear as influcenced by their ratio in the pollen cloud. Euphytica 33: 699-704. https://doi.org/10.1007/BF00021897

Williams J S, Der J P, de Pamphilis C W \& Kao T-H (2014). Transcriptome analysis reveals the same 17 S-Locus F-box genes in two haplotypes of the self incompatibility locus of Petunia inflata. Plant cells 26: 2873-2888. https://doi.org/10.1105/tpc.114.126920

Williams J S, Wu L, Li S, Sun P \& Kao T-H (2015). Insight into S-RNase-based self-incompatibility in Petunia: recent findings and future directions. Frontiers in Plant Science 6: 41. https://doi.org/10.3389/fpls.2015.00041

Zisovich A H, Raz A, Stern R A \& Goldway M (2010) Syrian pear (Pyrus syriaca) as a pollinator for European pear (Pyrus communis) cultivars. Scientia Horticulturae 125(3): 256-262. https://doi.org/10.1016/j.scienta.2010.03.01

Zisovich A H, Stern R A, Shafir S \& Goldway M (2004). Identification of seven S-alleles from the European pear (Pyrus communis L.) and the determination of compatibility among cultivars. The Journal of Horticultural Science and Biotechnology 79: 101-106. https://doi.org/.1080/14620316.2004.11511720

Zisovich A H, Stern R A, Shafir S \& Goldway M (2005). Fertilisation efficiency of semi and fully-compatible European pear (Pyrus communis) cultivars. The Journal of Horticultural Science and Biotechnology 80: 143-146. https://doi.org/10.1080/14620316.2005.11511906

Zuccherelli S, Tassinari P, Broothaerts W, Tartarini S, Dondini L \& Sansavini S (2002). S-allele characterization in self-incompatible pear (Pyrus communis L.). Sexual Plant Reproduction 15(3): 153-158. https://doi.org/10.1007/s00497-002-0145-5

Supplementary Table 1- $S$-allele compositions of pear cultivars

\begin{tabular}{|c|c|c|c|c|}
\hline No. & Cultivar name & S-Genotype & PCR based-Compatibility status & Region \\
\hline 1 & $190887(3-2)$ & $S_{6} S_{6}$ & Semi-compatible & Unknown \\
\hline 2 & $190887(3-1)$ & $S_{8} S_{8}$ & Semi-compatible & Aegean \\
\hline 3 & $240887(3-1)$ & - & Compatible & Aegean \\
\hline 4 & 22 & - & Compatible & Marmara \\
\hline 5 & 38 & $S_{6} S_{6}$ & Semi-compatible & Marmara \\
\hline 6 & A- 48 & - & Compatible & Unknown \\
\hline 7 & 133 & $S_{1} S_{6}$ & Semi-compatible & Marmara \\
\hline 8 & 200 GFAE & $S_{6} S_{6}$ & Semi-compatible & Black Sea \\
\hline 9 & $207 \mathrm{BF}(\mathrm{G})$ & - & Compatible & Black Sea \\
\hline 10 & $221 \operatorname{GFAE}(\mathrm{G})$ & $S_{6} S_{8}$ & Semi-compatible & Black Sea \\
\hline 11 & $223 \operatorname{GFAE}(\mathrm{G})$ & $S_{6} S_{6}$ & Semi-compatible & Black Sea \\
\hline 12 & A-2406 & $S_{1} S_{6}$ & Semi-compatible & Unknown \\
\hline 13 & Azdavay & $S_{6} S_{6}$ & Semi-compatible & Black Sea \\
\hline 14 & $\operatorname{Bağ}(G)$ & - & Compatible & Black Sea \\
\hline 15 & Bal Armut (Malatya) & $S_{6} S_{6}$ & Semi-compatible & Unknown \\
\hline 16 & Bey Armudu & $S_{6} S_{6}$ & Semi-compatible & Unknown \\
\hline 17 & Çankaya1 & $S_{6} S_{6}$ & Semi-compatible & Unknown \\
\hline 18 & Cennet (G) & $S_{6} S_{6}$ & Semi-compatible & Black Sea \\
\hline 19 & E 2473 Cinci & $\mathrm{S}_{8} \mathrm{~S}_{8}$ & Semi-compatible & Central Anatolian \\
\hline 20 & E 2501 Eğrişap & $S_{6} S_{6}$ & Semi-compatible & Central Anatolian \\
\hline 21 & E 2507 Pamukap & $S_{I} S_{I}$ & Semi-compatible & Central Anatolian \\
\hline 22 & E Rize & $S_{6} S_{6}$ & Semi-compatible & Unknown \\
\hline 23 & Fakaz (G) & $S_{1} S_{6}$ & Semi-compatible & Black Sea \\
\hline 24 & Gümüşhane (G) & $S_{1} S_{6}$ & Semi-compatible & Black Sea \\
\hline 25 & Gürpınar $(\mathrm{G})$ & $S_{1} S_{6}$ & Semi-compatible & Black Sea \\
\hline 26 & İğnesi (Malatya) & $S_{7} S_{7}$ & Semi-compatible & Unknown \\
\hline 27 & İncir (Malatya) & - & Compatible & Unknown \\
\hline 28 & Kantartopu & $S_{1} S_{I}$ & Semi-compatible & Black Sea \\
\hline
\end{tabular}


Supplementary Table 1 (Continue)- $S$-allele compositions of pear cultivars

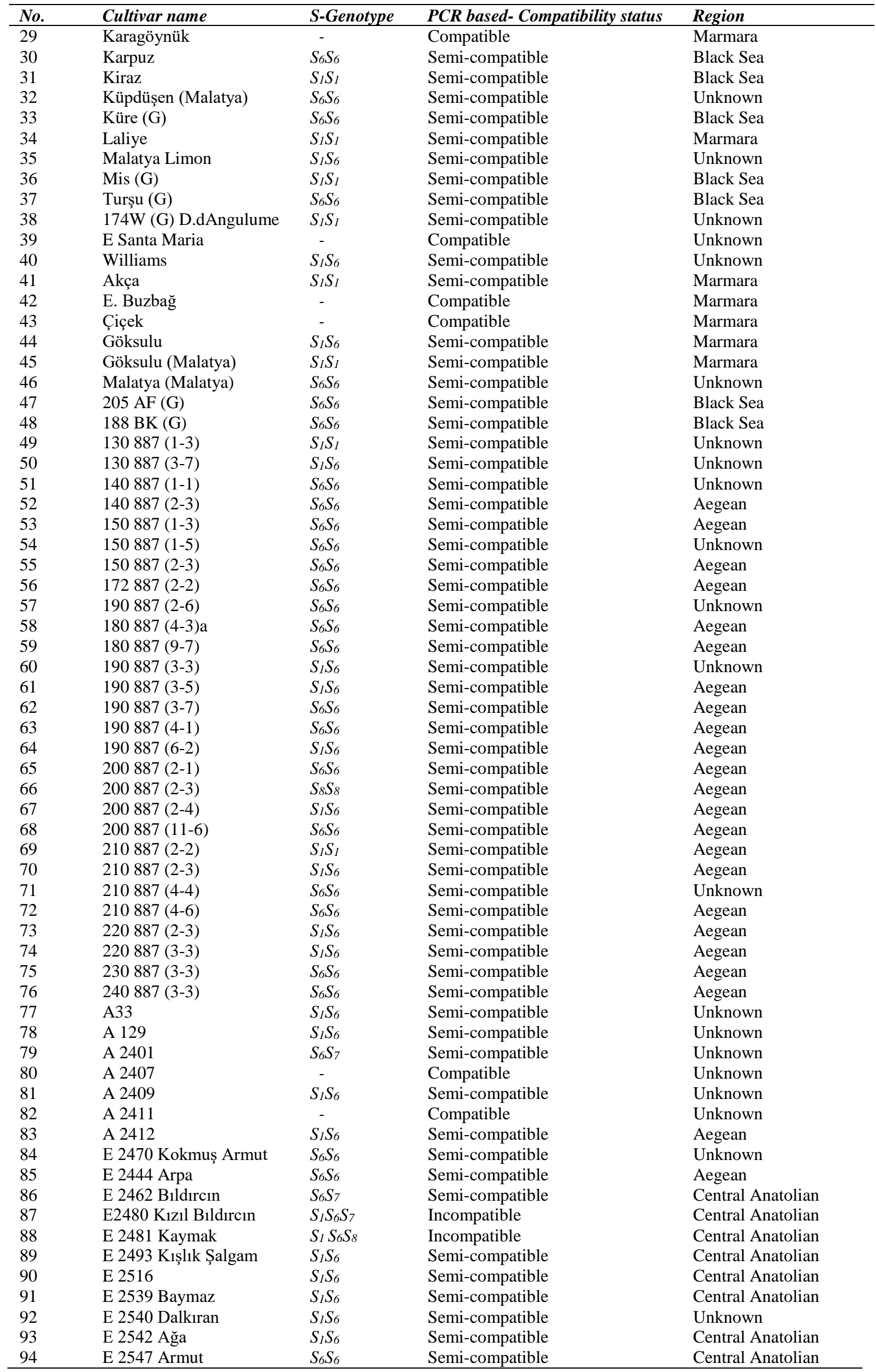


Supplementary Table 1 (Continue)- $S$-allele compositions of pear cultivars

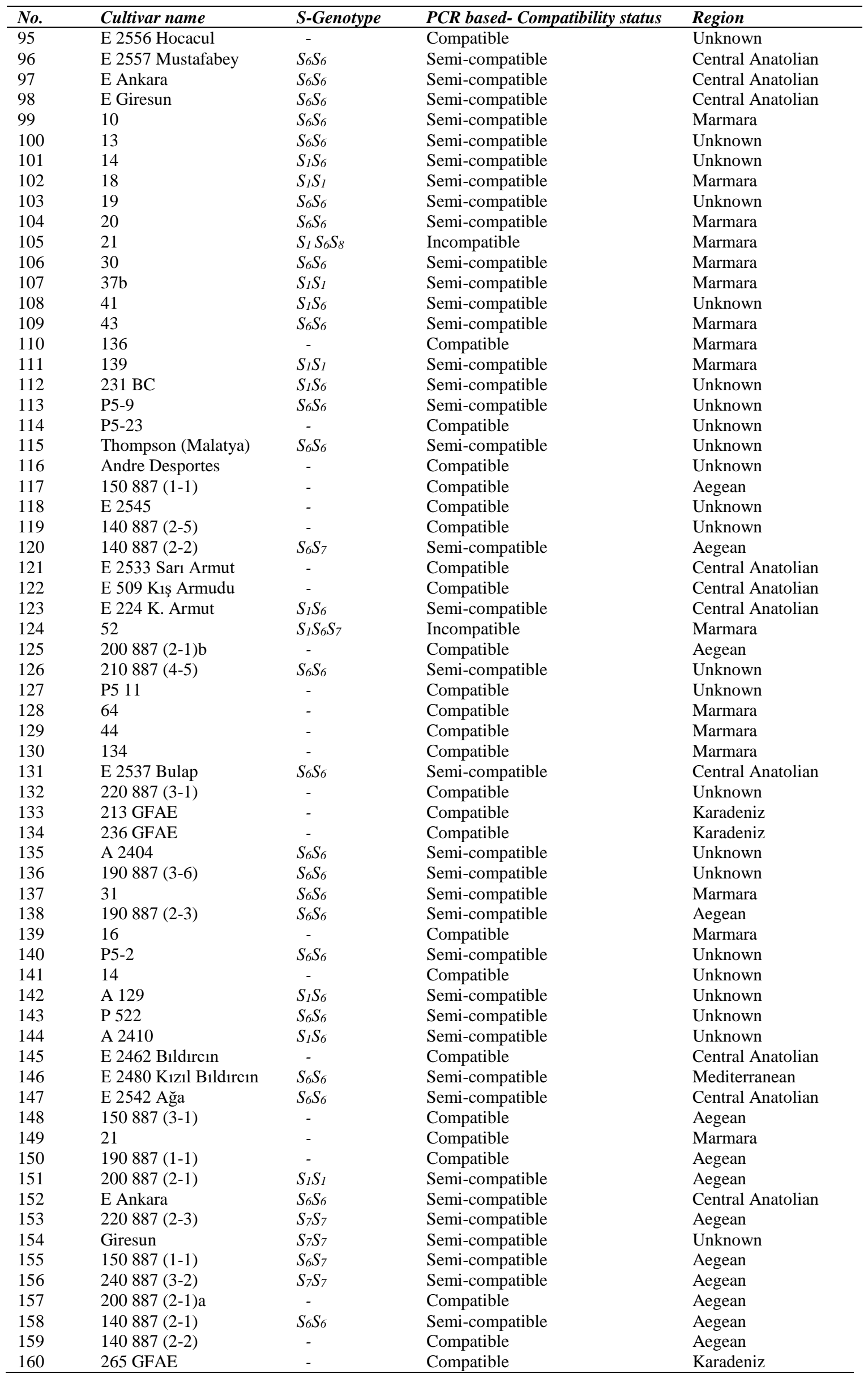


Supplementary Table 1 (Continue)- $S$-allele compositions of pear cultivars

\begin{tabular}{|c|c|c|c|c|}
\hline No. & Cultivar name & S-Genotype & PCR based-Compatibility status & Region \\
\hline 162 & E 2509 K. Armut & $S_{1} S_{6}$ & Semi-compatible & Unknown \\
\hline 164 & $200887(2-1) b$ & - & Compatible & Aegean \\
\hline 165 & E 2525 Ekşi Armut & $S_{6} S_{6}$ & Semi-compatible & Central Anatolian \\
\hline 166 & 44 & $S_{6} S_{6}$ & Semi-compatible & Marmara \\
\hline 168 & E 2537 Bulap & $S_{6} S_{6}$ & Semi-compatible & Central Anatolian \\
\hline 169 & $220887(3-1)$ & $S_{6} S_{6}$ & Semi-compatible & Unknown \\
\hline 170 & $235 \mathrm{P}$ & - & Compatible & Unknown \\
\hline 171 & A 2404 & - & Compatible & Unknown \\
\hline 172 & 31 & $S_{1} S_{6}$ & Semi-compatible & Marmara \\
\hline 177 & 45 & - & Compatible & Marmara \\
\hline 178 & 32 & - & Compatible & Marmara \\
\hline 179 & 138 & - & Compatible & Marmara \\
\hline 180 & A 135 & - & Compatible & Unknown \\
\hline
\end{tabular}

(C) 2022 by the author(s). Published by Ankara University, Faculty of Agriculture, Ankara, Turkey. This is an Open Access article distributed under the terms and conditions of the Creative Commons Attribution (CC BY) license (http://creativecommons.org/licenses/by/4.0/), which permits unrestricted use, distribution, and reproduction in any medium, provided the original work is properly cited. 